\title{
THE ACTION OF INSULIN IN MAN IN THE POSTABSORPTIVE AND POSTPRANDIAL STATES with a note on some applications of its action in determining muscle fuel in man*
}

\author{
David Rabinowitz, M.D., M.R.C.P., M.R.C.P.E.
}

KENNETH L. ZieRLER, M.D.

From the Department of Medicine, The Johns Hopkins University and Hospital, Baltimore, Maryland.

IT IS the purpose of this communication to review aspects of insulin's action on skeletal muscle and adipose tissue in vivo, from which arise some ideas concerning the day to day role of insulin in intact man. The experimental tool employed was the forearm of man. Subjects were studied during the morning hours after a 12 to 14 hour fast. Catheters were placed in the brachial artery (A) and in draining ipsilateral forearm deep (DV) and superficial (SV) veins. Forearm blood flow was measured by indicator dilution techniques based on the continuous infusion of Evans blue dye. Samples were taken at regular intervals from each of the catheters, and the concentration of selected metabolites was measured. A-DV concentration differences reflect, in the main, the metabolism of forearm muscle, but also undoubtedly of the adipose tissue that mingles with muscle; A-SV differences reflect chiefly the metabolism of subcutaneous adipose tissue.

The technique lends itself nicely to the examination of local effects of hormones. The hormone, insulin in the present experiments, is added to the solution containing the blue dye, and infused at constant rate into the brachial artery to produce the desired local concentration of hormone in the arm. The total amount of hormone is so small, however, that its arrival in the general circulation stimulates no measurable contra-response. Thus one observes as far as possible only the effects of the hormone on forearm tissues.

* Based on a talk given by D.R. during the tenure of a Wellcome Research Travel Grant.

These studies were supported by PHS Research Grants $A M 00750$ and $A M 05524$ and Graduate Training Grant 2A-5232, National Institute of Arthritis and Metabolic Diseases, U.S. Public Health Service and by a grant-in-aid from the Muscular Dystrophy Associations of America, Inc.

The senior author is an established investigator of the American Heart Association.
In the present study, the rates of infusion of insulin were so chosen that they resembled concentrations circulating in man during the day. The development by Yalow and Berson (1960) of a specific immunoassay for insulin has made possible studies of the normal fluctuations in plasma insulin. These workers have reported that in the postabsorptive period, 12 to 14 hours post cibum, plasma insulin levels are between 10 and $30 \mu \mathrm{U}$ per ml. Fifteen to 30 minutes after a glucose meal plasma insulin levels have risen steeply to values between 100 and $150 \mu \mathrm{U}$ per ml., after which there is a gradual return to basal concentration over a 4 to 6 hour period. In the light of these findings, experiments were performed with differing dose schedules of insulin so as to simulate local conditions in the arm (a) in the immediate postprandial period and (b) in the remote postabsorptive period.

\section{Effects of the postprandial insulin package}

Insulin was infused into the arms of 15 normal subjects at a rate of $100 \mu \mathrm{U} / \mathrm{kg} . / \mathrm{min}$. for 26 minutes (Andres, Baltzan, Cader and Zierler, 1962; Rabinowitz and Zierler, 1962). This achieves a concentration of insulin of about $300 \mu \mathrm{U}$ per ml. brachial arterial plasma, or roughly twice the peak endogenous concentration in plasma in the immediate postprandial period. The metabolic responses observed are summarized in Fig. 1. (1) Glucose uptake by forearm tissues was increased many fold: uptake by muscle increased by a factor of 12 , uptake by adipose tissue by a factor of 6. (2) Potassium moved, in the net, into forearm muscle and into forearm adipose tissue. (3) Free fatty acid (FFA) release from forearm adipose tissue was inhibited. (4) The RQ (respiratory quotient) of forearm muscle, 0.7 basally, did not change.

This is an important, albeit indirect piece of evidence that the glucose taken up' was not 


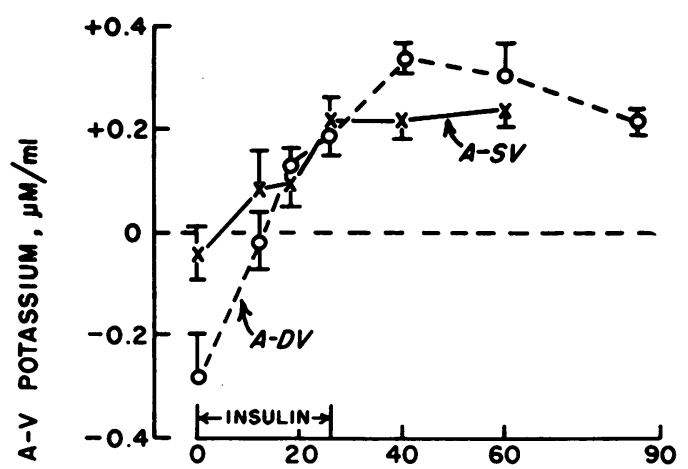

centration circulating in the basal state. Fig. 2 shows a typical response in one subject. At this concentration insulin did not enhance glucose translocation into muscle or adipose tissue. However, insulin did produce potassium movement into both tissues and inhibited FFA release from adipose tissue. In other words, at concentrations of insulin similar to those circulating in the basal state, effects of the hormone on $\mathrm{K}$ and FFA are segregated from effects on glucose. The dose response curves of insulin's action on glucose, $\mathrm{K}$ and FFA are not superimposable but are similar with respect to both muscle and adipose tissue. Figure 3 illustrates the curves constructed from effects of insulin, 1,10 and $100 \mu \mathrm{U} / \mathrm{kg}$./min., on A-SV differences in man. The curves shown hold equally well both for muscle and for adipose tissue.

It is stressed that differences in insulin responsiveness do not appear to lie in the responding tissue: they reside in the mechanism by which glucose is translocated into peripheral cells compared to the mechanisms whereby $\mathrm{K}$ movement is enhanced and FFA release in inhibited.

There are several interesting implications in these differences in sensitivity of differente metabolic processes to insulin. Firstly it appearso that insulin may serve a somewhat different function in man during postprandial and postabsorptive periods. Immediately after a meal when plasma insulin concentrations are maximal, insulin oversees a period of storage; storage of $\mathrm{K}$ in muscle and in adipose tissue, storage of glucose, as glycogen in muscle, and as triglyceride in adipose tissue. Repletion of adipose tissue depots is further aided by blockade of FFA escape from the fat cell.

During the postabsorptive period, on the other hand, plasma insulin levels are set at a concentration which is impotent in promoting peripheral glucose uptake. As we shall see presently, skeletal muscle, an insulin-sensitive cell, appears to rely heavily on lipid combustion in the basal state. The nerve cell, which is not insulin-sensitive, utilizes chiefly glucose to which it is freely permeable. If glucose were diverted by insulin into peripheral muscle and adipose tissue during food-free intervals, its availability to the nervous system might be compromised. Since in fact basal plasma insulin levels are too low to promote peripheral glucose uptake, glucose uptake by total skeletal muscle is quantitatively small, and nervous tissues abstract about $80 \%$ of basal hepatic glucose output. local arterial concentration by about $30 \mu \mathrm{U}$ per ml. or only two or three times the con-

\section{Effects of the postabsorptive insulin package}

In an attempt to learn more about the role of insulin during food-free intervals, insulin was infused into nine normal subjects at a rate of $10 \mu \mathrm{U} / \mathrm{kg}$./min. for either 26 or 35 minutes (Zierler and Rabinowitz, 1963). This raised

combusted, since the respiratory quotient dur-
ing glucose oxidation is unity. Thus, although insulin facilitated the translocation of glucose into muscle and adipose tissue, there was no evidence that the glucose taken up was being used as fuel. The excess glucose then was stored, presumably as glycogen.

FIG. 1.-Response of glucose and potassium A-DV and A-SV differences, and FFA A-SV differences in control subjects to the post-prandial size insulin package. 


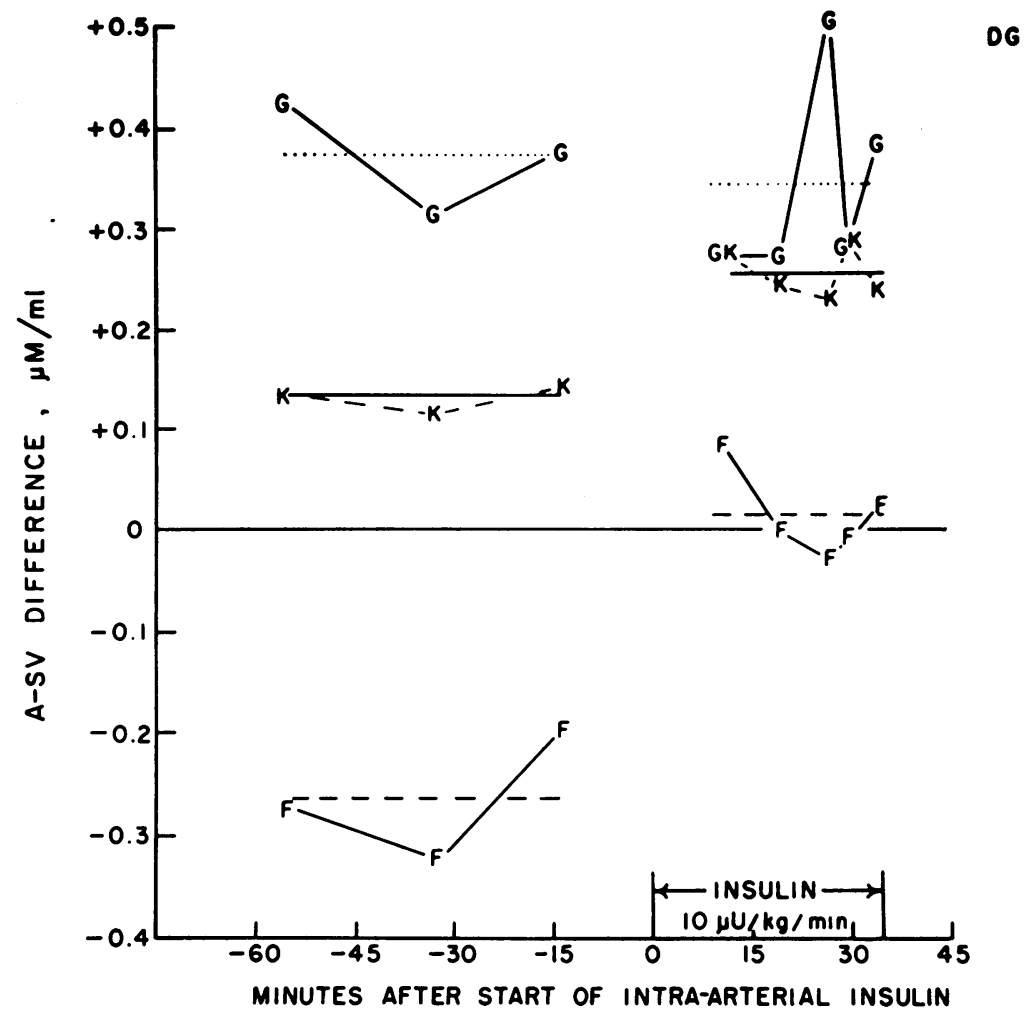

FIG. 2.-Effect of postabsorptive insulin package on forearm A-SV glucose, potassium and FFA differences in one subject. Glucose translocation is not enhanced. However, this dose of insulin promotes $\mathrm{K}$ movement into the arm and inhibits FFA release from forearm adipose tissue. This response is representative of our experience in both DV and SV.

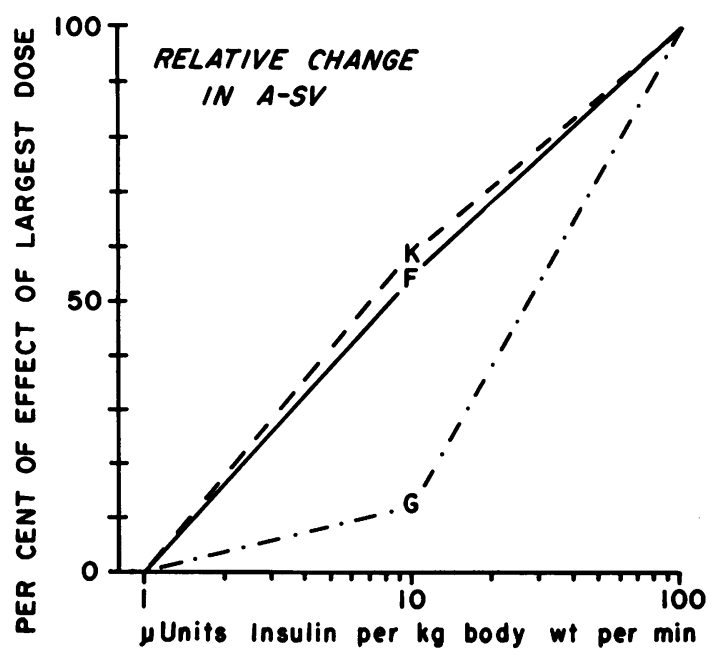

FIG. 3.-Dose response curves for insulin in the arm. Response in the superficial bed is illustrated; response in the deep bed is similar. The concentration of insulin $(10 \mu \mathrm{U} / \mathrm{kg}$. $/ \mathrm{min}$. $)$ which is large enough to promote FFA and potassium movement is too small to translocate glucose. Units on the X-axis may be converted to $\mu \mathrm{U}$ insulin per ml. brachial arterial plasma by considering that infusion of $1 \mu \mathrm{U} / \mathrm{kg}$./min. yields a local insulin level of about $3 \mu \mathrm{U} / \mathrm{ml}$. 
The small concentration of insulin present in the basal state is sufficient, however, to retard escape of FFA from adipose tissue. Skeletal muscle burns fat in the form of FFA, a subject which will be discussed in more detail later. The source of plasma FFA is the adipose tissue cell. Mobilization of FFA from adipose tissue is under endocrine control, being encouraged during food-free intervals by several hormones including human growth hormone. Plasma insulin is the only hormone, among those so studied, whose action retards release of FFA. Presumably, then, the function of insulin in the basal state is to "tone-down" the release of FFA, thereby preventing its excessive accumulation in plasma, which might have several undesirable consequences, for example, excessive ketone formation and acidosis.

As far as potassium is concerned, it appears that in the basal state insulin serves to reduce escape of $\mathrm{K}$ from its chief intracellular source, skeletal muscle, an action which is quite independent of its action on glucose.

In summary then, insulin functions in man both during feasting and during fasting, promoting carbon and $\mathrm{K}$ storage during periods of "feast", and reducing $K$ and FFA escape from muscle and adipose tissue during "fast".

\section{Some applications of the action of insulin}

The use of insulin has proved to be a potent tool permitting the role of FFA as substrate for skeletal muscle in situ to be quantified. Several years ago Andres, Cader and Zierler (1956) examined A-DV differences of glucose across the forearm of man during the basal state. Uptake of glucose by the arm was exceedingly small: only 2 to $3 \%$ of arterial glucose was abstracted by the arm, an amount which, even if completely oxidized, was sufficient to account for no more than $20 \%$ of forearm oxygen consumption.

This calculation is arrived at as follows:

1. Mean basal A-DV glucose across the arm $=0.14 \mu \mathrm{M} / \mathrm{ml}$.

2. Mean basal DV-A lactate $=0.12 \mu \mathrm{M} / \mathrm{ml}$. That is, lactate escapes from forearm skeletal muscle into venous plasma, even under resting basal conditions.

3 . Since 1 mole of glucose yields 2 moles of lactate, the observed lactate leak accounts for an $\mathrm{A}-\mathrm{V}$ glucose of $0.12 / 2 \mu \mathrm{M} / \mathrm{ml}$.

4. Mean basal A-DV glucose available for oxidation $=[0.14-0.12 / 2]=0.08 \mu \mathrm{M} / \mathrm{ml}$.

5 . The oxidation of 1 mole of glucose requires 6 moles of oxygen. Thus oxidation of
$0.08 \mu \mathrm{M} / \mathrm{ml}$. glucose requires $[0.08 \times 6]$ or $0.48 \mu \mathrm{M} / \mathrm{ml}$. oxygen.

6. Mean basal A-DV oxygen $=3.02 \mu \mathrm{M} / \mathrm{ml}$. Thus [3.02-0.48]/3.02 or $84 \%$ of oxygen is not accounted for by glucose oxidation.

At the time these first observations were made. (Andres, Baltzan, Cader and Zierler, 1956), they were at odds with orthodox notions. Today they are no longer so controversial. Glucose uptake by forearm is low in the basal state because the membranes of adipose tissue and of skeletal muscle are only poorly permeable to glucose and (1) as we have just seen plasma insulin levels during the basal state are not high enough to promote glucose translocation (see Fig. 2) whereas (2) plasma HGH (human growth hormone) which decreases glucose uptake by peripheral tissues, circulates at high concentrations in the postabsorptive period (Glick, Roth, Yalow and Berson, 1963).

What is the major fuel of intact muscle in the basal state?

Several clues have suggested that the missing substrate is lipid in nature. The RQ of forearm muscle is 0.7 , which suggests the oxidation of long-chain fatty acids. Dole (1956) and Gordon and Cherkes (1956) first drew attention to as small fraction of total plasma lipid whicl circulates as free or unesterified fatty acid which turns over with extraordinary rapidity? and, therefore, may be the most likely candidate as an important fuel for intact skeletal muscle.

Despite extensive observations, this laboratory has been unable to show that A-DV FFA differences are consistently positive (Baltzan, Andres, Cader and Zierler, 1962). The mean A-DV FFA difference among a large series of subjects was not distinguishable from zero. It was suggested that anatomical reasons may have been responsible for failure to find FFA uptake by muscle (Fig. 4). The deep vein we catheterize drains not only muscle but also that adipose tissue contiguous to muscle. There is undoubtedly some admixture from superficial forearm territory, including adipose tissue. It is possible, therefore, that skeletal muscle does in fact take up FFA, but addition of FFA from adipose tissue to deep venous blood obscures the A-V difference (Fig. 4). (Baltzan and others, 1962).

We can test this hypothesis and unmask FFA uptake by muscle by administering an agent which (1) inhibits FFA release from adipose tissue but (2) is without influence on peripheral FFA uptake. Insulin appears to fulfil these criteria. We have already shown 


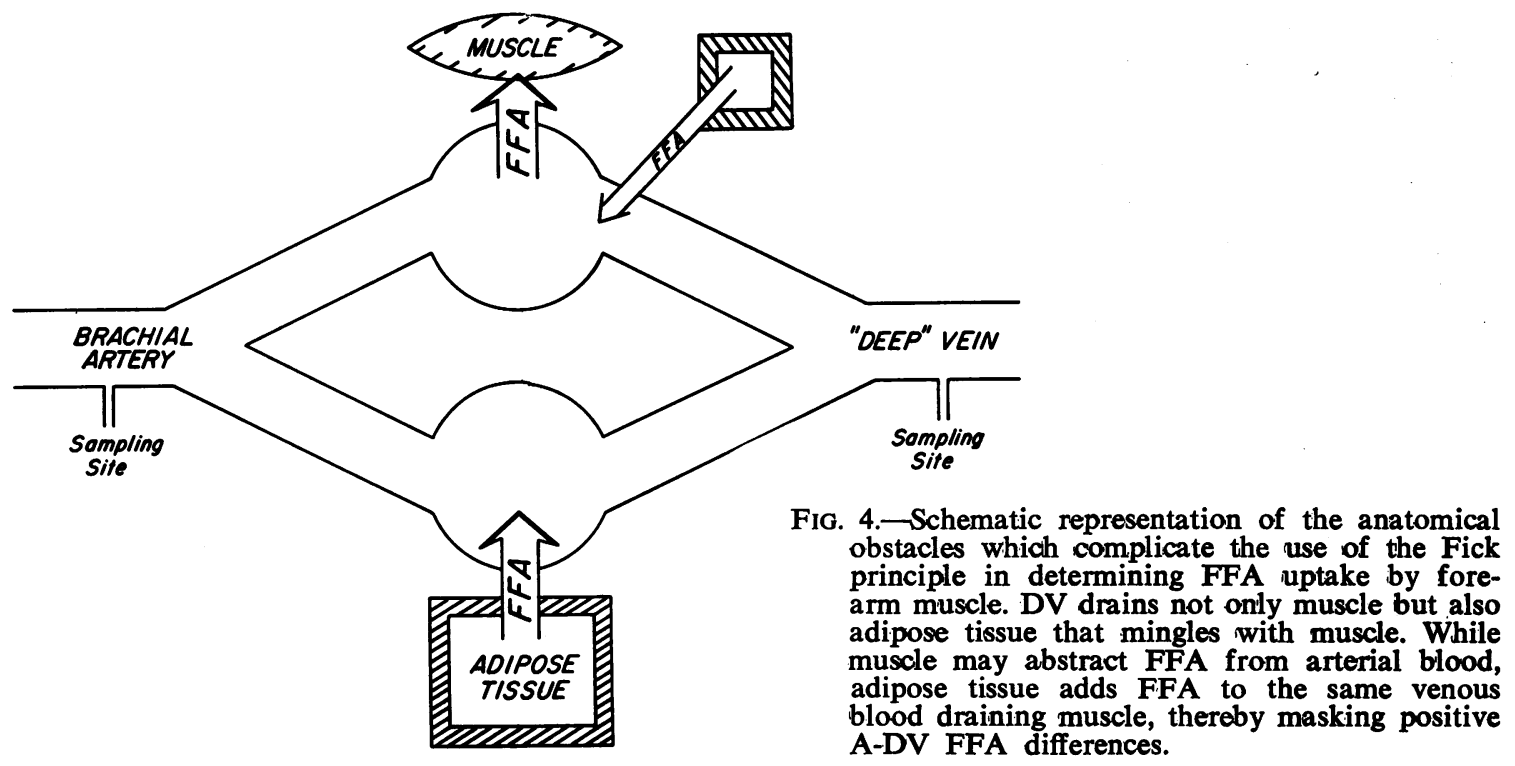

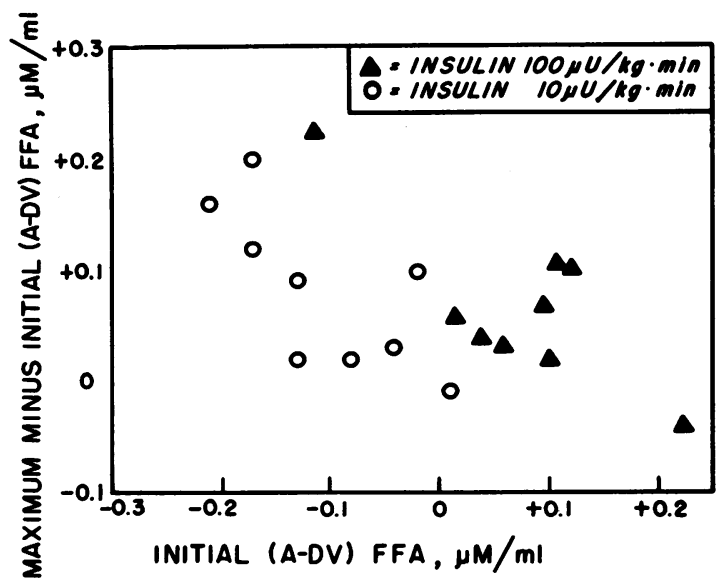

that insulin, $100 \mu \mathrm{U} / \mathrm{kg}$./min. does inhibit FFA release from forearm adipose tissue (Fig. 1). The following study suggests that the second desideratum is also met: Bierman, Sohwartz and Dole (1957), studying effects of palmitic acid-1-C ${ }^{14}$ infusion into the dog, observed that the administration of insulin did not change the rate of decline of plasma radio-activity and caused plasma specific activity to rise. These two observations indicated that insulin had cut down FFA output but had not influenced the peripheral disposal of FFA.

We are probably justified then in using insulin to unmask FFA uptake by muscle. In nine subjects on whom data are available, insulin, $100 \mu \mathrm{U} / \mathrm{kg}$./min., unmasked a mean maximal A-DV FFA of $0.11 \mu \mathrm{M} / \mathrm{ml}$. This figure can be used to calculate the percentage of foreanm oxygen uptake which can be accounted for by FFA oxidation (FFA/ $/ 0_{2}$ ). Since 1 mole of FFA requires 25 moles of oxygen for complete combustion and since FFA is measured in the plasma fraction and oxygen in whole blood, the following equation obtains-

FFA $/ 0_{2}=($ A-DV $)$ FFA $\times 25 \times$ plasmacrit

$$
\text { (A-DV) } 0_{2}
$$

$$
=\frac{0.11 \times 25 \times 0.6}{3.02}=0.55
$$


That is, more than half forearm oxygen consumption can be accounted for by FFA combustion. This is of course a minimum figure, since we cannot be absolutely sure that FFA output has been totally obliterated by insulin.

If insulin only influences FFA output from adipose tissue, then the insulin-induced change in A-DV FFA should be a linear function of basal A-DV FFA. That is, the higher the initial A-DV FFA (and thus, by inference, the less the adipose tissue admixture) the smaller should be the change effected by insulin. Fig. 5 demonstrates that this relationship holds true for both the $100 \mu \mathrm{U} / \mathrm{kg} . / \mathrm{min}$. and $10 \mu \mathrm{U} / \mathrm{kg}$. $/ \mathrm{min}$. insulin doses.

There remains the question of whether skeletal muscle and not adipose tissue abstracts FFA from arterial plasma. This is an important consideration since excised adipose tissue readily takes up FFA from the supporting medium. Under in vivo conditions, however, adipose tissue competes poorly for FFA. Bragdon and Gordon (1958) fed labelled palmitic acid to the rat and assayed various body tissues for appearance of radioactivity. Total adipose tissue took up only 1 to $2 \%$ of the label, whether or not endogenous insulin secretion had been stimulated by a prior oral glucose meal.

We suggest, therefore, that basal FFA uptake closely resembles the FFA uptake unmasked by insulin and accounts for at least half forearm oxygen consumption. We are at present attempting to develop more direct methods for quantifying FFA uptake by skeletal muscle.

\section{Summary}

The role of insulin in man in the postprandial and the post-absorptive periods is discussed. In the first hour or two after a meal, plasma insulin is high enough (a) to promote translocation of glucose and potassium into muscle and fat and (b) to inhibit FFA release from adipose tissue. In the remote postabsorptive period, plasma insulin is too low to promote glucose movement but is still high enough ta. influence $K$ and FFA movement. Insulin uns masks sufficient FFA uptake by skeletal muscto to account for at least half its oxygen cons sumption.

\section{REFERENCES}

Andres, R., Baltzan, M. A., CADER, G., and Zierler, K. L. (1962): Effect of Insulin on Carbohydrate Metabolism and on Potassium in the Forearm of Man, J. clin. Invest., 41, 108.

ANDres, R., CADER, G., and Zierler, K. L. (1956) $\vec{\omega}$ The Quantitatively Minor Role of Carbohydratg in Oxidative Metabolism by Skeletal Muscle in Intact Man in the Basal State. Measurements of Oxygen and Glucose Uptake and Carbon Dioxide and Lactate Production in the Forearm, ibid:

Baltzan, M. A., Andres, R., Cader, G., and Zierlep̣̂, K. L. (1962): Heterogeneity of Forearm Meta' bolism with Special Reference to Free Fatty Acidso ibid, 41, 116.

Bierman, E. L., Schwartz, I. L., and Dole, V. Pب (1957): Action of Insulin on Release of Fattyn Acids from Tissue Stores, Amer. J. Physiol. 191 359.

BraGdon, J. H., and Gordon, R. S., Jr. (1958): Tissuê Distribution of $\mathrm{C}^{14}$ after the Intravenous Injection of Labelled Chylomicrons and Unesterified F\&ty Acids in the Rat, J. clin. Invest., 37, 574.

Dole, V. P. (1956): A Relation between Non-esteric fied Fatty Acids in Plasma and the Metabolifnp of Glucose, ibid, 35, 150.

Glick, S. M., RoTh, J., YAlow, R. S., and Berson S. A. (1963): Hypoglycemia: Potent Stimulus to Growth Hormone Secretion, ibid, 42, 935.

Gordon, R. S., Jr., and CHERKES, A. (1956): Un esterified Fatty Acid in Human Blood Plasma,
ibid, 35, 206.

RABINOWITZ, D., and ZiERLER, K. L. (1962): Role of Free Fatty Acids in Forearm Metabolism, Quantitated by Use of Insulin, ibid, 41, 2191.

YALOW, R. S., and BERSON, S. A. (1960): Immuno: assay of Endogenous Plasma Insulin in Man, ibid 39, 1157.

ZiERLER, K. L., and RABINOWITZ, D. (1963): Inde pendence of Insulin Action on Potassium and on 3 . Fatty Acids from its Action on Glucose, Trans Ass. Amer. Phycns., 76, 245. 